\title{
How Knowledge About Physical Activity Is Impacted By School Institution, Grade Level, and Gender Throughout High School Years in France?
}

\author{
Joseph Gandrieau, ${ }^{1}$ Christophe Schnitzler, ${ }^{2}$ Thibaut Derigny, ${ }_{1}^{1}$ Clément Lléna, ${ }^{1}$ \\ Alexandre Mouton, ${ }^{3}$ and François Potdevin ${ }^{1}$ \\ ${ }^{1}$ Univ. Lille, Univ. Artois, Univ. Littoral Côte d'Opale, ULR 7369-URePSSS—Unité de Recherche Pluridisciplinaire \\ Sport Santé Société, Lille, France; ${ }^{2}$ UR 1342 E3S, Université de Strasbourg, Strasbourg, France; \\ ${ }^{3}$ Department of Sport and Rehabilitation Sciences, University of Liège, Liège, Belgium
}

\begin{abstract}
Purpose: Despite its relevance for the training of a well-rounded physically literate individual, the development of knowledge about physical activity (KPA) is understudied. We examined how KPA is differentiated and evolves according to grade level, gender, and type of school attended by an adolescent. Method: A reliable KPA assessment tool was developed. A three-way analysis of variance was used to analyze $z$ scores on the effects of gender, grade level, and type of school on five different dimensions of knowledge. Results: The reliability was validated. Statistically significant interactions were revealed between grade and school institution on KPA $z$ scores. Main results showed that vocational schools displayed significantly lower levels, compared to traditional ones. The only increase in knowledge according to grade was noticeable only in traditional schools. Results revealed no significant gender differences. Discussion: The French physical education system does not seem to provide an adequate level of KPA, especially in vocational schools.
\end{abstract}

Keywords: adolescent, knowledge assessment, physical activity awareness, physical literacy

Many recent findings on the lack of physical activity (PA) in people across the lifecourse (e.g., Guthold et al., 2018) have ranked this problem as a major health and international challenge (Kohl et al., 2012). In this alarming physical inactivity context, UNESCO (2015) showed that Quality Physical Education can contribute to the development of physically active citizens on a long-term basis (Pate et al., 2006). This issue is becoming increasingly critical due to the growing demand for adolescent's autonomy in their relationship to PA (Muller, 2018).

The current literature and opinions in political organizations seem to converge toward the idea of a holistic PA education, provided through the concept of "physical literacy" (UNESCO, 2015; Whitehead, 2001, 2010, 2019). Considering physical education (PE) from the perspective of physical literacy involves designing educational programs that simultaneously seek to develop the physical, knowledge, psychological, and social dimensions of each individual through engagement in PA (Cairney et al., 2019; Keegan et al., 2019).

However, these dimensions have not been studied with the same attentional focus in the literature. As Edwards et al. (2017) pointed out, cognitive dimension remains insufficiently studied although its consistent consideration in physical literacy related literature (Cale \& Harris, 2018). "The Cognitive domain focuses on the development of knowledge and understanding required for movement and physical activity" (Sport Australia, 2020, p. 2). In particular, while the literature is growing on the physical dimension (e.g., Barnett et al., 2016; Hulteen et al., 2018), there is limited research on the development and evolution of knowledge about PA

Gandrieau (joseph.gandrieau@univ-lille.fr) is corresponding author, (D)https:// orcid.org/0000-0002-4318-9574
(KPA; Hunter et al., 2014; Keating, 2003) especially during high school years.

Knowledge differs from an opinion because it requires a substantive justification based on established facts rather than beliefs, wishes, and aspirations. In that regard, KPA may be defined as "information that a person knows and can convey" about PA (Keegan et al., 2019, p. 5). KPA needs to be gained from substantive applied scientific sources and is in a dynamically evolving state that can be developed and improved throughout life (Whitehead, 2010). In a definition of physical literacy, Whitehead (2019) includes the knowledge needed to improve performances in different PA types related to social activities and the health benefits of PA. Knowledge is included in explanatory models of PA engagement (Cairney et al., 2019; Parcel \& Baranowski, 1981; Rudd \& Glanz, 1990) and some empirical links between knowledge and PA levels are highlighted in the literature (Chen et al., 2017; Fredriksson et al., 2018). These studies show that level of knowledge alone is not sufficient to explain the whole process of engagement in PA (Cairney et al., 2019; Ennis, 2007; Placek et al., 2001). However, knowledge remains a key variable for a long-term involvement in PA, as recognized in recommendations of important organizations such as the World Health Organization which advocate the value of "knowledge of the multiple benefits of regular PA" (World Health Organization, 2020, p. 17). Thus, given the importance of KPA, it seems necessary to include or reinforce their teaching in PE programs (Cale \& Harris, 2018).

Formal education at school is considered a cornerstone of knowledge development (Tanner \& Tanner, 2006), and KPA is no exception, as the school environment has the potential to impact a whole generation of students (Van Sluijs et al., 2007). KPA should, therefore, be seen as an important part of a long-term strategy to promote lifelong PA. Research shows that it is possible to develop KPA throughout the school years via the curriculum (Blanchard et al., 
2020; Longmuir et al., 2018). However, the level of understanding appears to be low in the populations studied (Chen \& Nam, 2017; Keating et al., 2009; Morrow et al., 2004; Yona et al., 2019), suggesting a limited development of this kind of knowledge with age during school years. However, the relationship between KPA level and age remains unclear. Blanchard et al. (2020) and Longmuir et al. (2018) showed that KPA of Canadian youth increases from 9 to 12 years of age and from 12 to 15 years of age. Conversely, the 25-44 years of age group are more knowledgeable than those aged 44 years and older (Kay et al., 2014). In adulthood, KPA level is also influenced by gender with significantly higher KPA scores in women (Bennett et al., 2009; Kay et al., 2014; Moore et al., 2010). However, this difference is not clearly apparent in the literature during childhood or adolescence (Blanchard et al., 2020; Longmuir et al., 2018) while studies show higher performance among females in academic subjects (OCDE \& Bartilla, 2017), which calls into question the gender specificity of KPA. Finally, KPA score is correlated with level of education (Kari et al., 2020; Kay et al., 2014) suggesting that vocational students, who are typically less theory oriented throughout their formal education, might develop less KPA than students enrolled in a traditional school (DuruBellat \& Perretier, 2007). A vocational school is a secondary educational institution designed to provide vocational education required to complete the tasks of a particular job. On the contrary, the traditional schools aim at a more general education without direct connection with an immediate career goal.

Given the importance of KPA to physical literacy (Cale \& Harris, 2018; Ennis, 2015), we anchor this study in the physical literacy framework (Cairney et al., 2019) and specifically in the KPA domain. In France, formal PE programs offer three explicit categories of knowledge to be taught to the students, including: (a) principles of efficacy to effectively engage in PA (Badminton: "Various solutions to build the point: make the rally last to tire the opponent and/or take the opponent in a hurry, while varying the trajectories" cited in Ministère de L'Education Nationale, 2010), (b) knowledge related to training according to the objectives of maintaining health or achieving a performance ("Know and adjust different training parameters" cited in Ministère de L'Education Nationale, 2010), and (c) knowledge relating to sports culture in order to understand the value and meaning of different activities in a society or group (e.g., "access to cultural heritage" cited in Ministère de L'Education Nationale, 2010). More implicitly, two additional categories of KPA can be identified: (d) knowledge about scientific recommendations (e.g., "the principles of a healthy habitus [ ... ] regularity of physical practice" cited in Ministère de L'Education Nationale, 2010), and (e) knowledge on the benefits of PA (e.g., "include the beneficial effects of regular physical activity with increasing independence throughout life" cited in Ministère de L'Education Nationale, 2010). Thus, an assessment of KPA for French students can focus on these five dimensions of knowledge.

The purpose of this study was to assess students' KPA by grade level, school, and gender, in relation to these five categories identified in the French PE curriculum. We hypothesized that the level of KPA evolved with the grade level but remained relatively low, especially for students undertaking education at a vocational school. Also, despite differences in academic knowledge, we hypothesized that boys were equally as knowledgeable as girls for KPA because of the importance of the gender issue in French PE policies. Indeed, since 2018, this issue is prominent within the French educational policy with, for example, an "equality referent" in each school and a specific training for all educational teams (Ministère de l'Education Nationale, 2018).

\section{Method}

\section{Constructions of the Questionnaire and the Evaluation's Scale}

\section{Identification of Categories}

In order to create a questionnaire to score the level of French adolescents' KPA, we conducted a qualitative analysis of French's PE programs. Taking inspiration from the Grounded Theory method (Strauss \& Corbin, 1994) we identified five categories of KPA in the French PE curriculum (Table 1). A research team of two academics and two practitioners designed the items to assess each category. Academics are PhDs in PA and sports science, and practitioners are PE teachers and experts in physical literacy ( $>5$ years of experience). Each item was discussed until unanimous consensus was reached. At the end of this stage, the tool consisted of 44 items.

\section{Development of a Scale Measurement}

Based on the five knowledge categories, the initial research team conducted a double-step process. The first step was to create the items. The four initial members worked independently on a battery of items to assess each category of knowledge. Items were shared, discussed, and finally agreed upon in case of total unanimity. Consensus was reached on the completeness of the items, their relevance to the knowledge categories, and the target population.

The second step was based on this item's selection. Three members of the initial research team designed a scale measurement for each category of questions (open-ended questions and closedended questions) by a triangulation method (Lincoln \& Guba, 1985). The category scales were verified by a new group of expert PE teachers enrolled for their level of expertise for each category. Qualitative interviews allowed the proposals to evolve before being resubmitted to the consensus of the initial. At the end of these two steps, we followed the recommendations of Lawshe (1975) to consider the acceptance standard of content validity ratio (content validity ratio $\geq 0.99$ ) to assess the content validity (Haynes et al., 1995).

Each item of the questionnaire is scored between 0 and 2 points by researchers with an 0.5 incremental scale. A total of 0.5 , $1,1.5$, and 2 points represent respectively inadequate, low, sufficient, and excellent level of KPA. The total score represents the sum of all the five categories' scores, to obtain a score between 0 and 10 points. The closer the score to 10 is, the higher the KPA level is.

To examine the interrater reliability, three PE teachers were recruited and trained (30 $\mathrm{min}$ ) to assess the responses of a randomly selected sample of participants $(n=100)$. We calculated the intraclass fidelity coefficient for each item (Bartko, 1966; Shrout \& Fleiss, 1979) and conducted the Krippendorff alpha test (Hayes \& Krippendorff, 2007). Items which did not reach recommended thresholds $(p<.05$; intraclass correlation coefficient $>.7$; Krippendorff alpha $>.7)$ were modified and retested. When the value was still unsatisfactory following a second assessment, the item was discarded $(n=8)$.

\section{Recruitment of Participants}

In accordance with French law on data protection, an authorization to conduct this study was given by Data Protection Officer of the University of Lille under number 202037 and the Ethical committee of University of Lille (France). This authorization procedure secures data storage and guarantees the anonymity of participants. 
Table 1 Categories of Physical Activity Knowledge

\begin{tabular}{ll}
\hline Benefits & $\begin{array}{l}\text { Knowledge of benefits of physical activity and risks } \\
\text { of physical inactivity }\end{array}$ \\
Culture & $\begin{array}{l}\text { Knowledge of sports culture in a society, group, } \\
\text { and community }\end{array}$ \\
Principles & $\begin{array}{l}\text { Knowledge of principles of efficacy in sports } \\
\text { activities }\end{array}$ \\
Recommendations & $\begin{array}{l}\text { Knowledge of World Health Organization } \\
\text { recommendations }\end{array}$ \\
Training & Knowledge related to training process \\
\hline
\end{tabular}

The questionnaire, in a digital version (Framasoft, Lyon, France), was distributed throughout France in a public forum for PE teachers on a professional social network. The volunteer teachers recruited their students through an online questionnaire. The recruitment process resulted in 764 adolescents (between 9th and 12th grades) volunteering to participate in the study. Distribution by grade, school, and gender is shown in Table 2 . We excluded participants $(n=28)$ when they did not answer the verification questions correctly (two questions).

\section{Measurement of Participant Scores}

The KPA global questionnaire consisted of three parts: (a) general and sociological information (e.g., gender, school, and grade), (b) five categories of KPA (36 items), and (c) verification questions $(n=2)$.

\section{Ranking of KPA in Relation to Grade Levels: Calculation of the Z Score}

Descriptive analyses were undertaken of mean values of KPA scores according to each dimension and independent variables (gender, grade, and school type). Normality ( $p>.05$; Shapiro-Wilk test) and homogeneity of variance of the data $(p<.05$; Levene test) were tested. Friedman's analysis of variance was used to compare mean KPA score according to each dimension.

As the equality of variance in the data assumption was violated, we decided to standardize expression of test performance by converting the score of each participant into $z$ scores, allowing us to compare each participant scores to the distribution average using $S D$ units (Aguert \& Capel, 2018). This method reduces the limitations of our scale by assigning a score based on others in the distribution and real scores. We calculated the $z$ scores with the formula $z=(x-\mu) / \sigma$ with $x$ representing KPA score, $\mu$ the mean value KPA score of the population, and $\sigma$ the KPA $S D$ of the population (Aguert \& Capel, 2018).

\section{Statistical Analyses}

We calculated mean and $S D$ of $z$ scores in each KPA dimension differentiated by gender, grade, and school type (traditional or vocational). A three-way analysis of variance on $z$ scores (Gender $x$ School $\times$ Grade) was used to detect any significant main and interaction effects of each independent variable on KPA $z$ scores. Partial eta squared values $\left(\eta_{\mathrm{p}}^{2}\right)$ were used to examine the effect sizes with a 95\% confidence interval. We followed the recommendations of Cohen (1988) to consider the effect small when $\eta_{p}^{2}>.01$, medium when $\eta_{\mathrm{p}}^{2}>.06$, and large when $\eta_{\mathrm{p}}^{2}>.14$.

Between-group differences (vocational vs. traditional) for the same grade and within-grades differences were analyzed by Tukey
Table 2 Participant Description

\begin{tabular}{lccccc}
\hline Participants & Total & Girls & Boys & Vocational $^{\mathbf{a}}$ & General \\
\hline$n$ & 748 & 463 & 285 & 124 & 624 \\
9th Grade & 195 & 117 & 78 & 17 & 178 \\
10th Grade & 235 & 147 & 88 & 43 & 192 \\
11th Grade & 212 & 129 & 83 & 34 & 178 \\
12th Grade & 106 & 70 & 36 & 30 & 76 \\
\hline
\end{tabular}

${ }^{\mathrm{a}}$ In France, the vocational educational program contains around $30 \%$ of students.

post hoc tests. The presence of outliers was assessed. Normality, homoscedasticity, and interdependence of the residuals were checked for each score (Grubbs test, Jarque-Bera test, Bptest, and Durbin Watson test). Level of statistical confidence was set at $p<.05$.

The free R software (version 1.2.50.33; Rstudio, Boston, MA) with different packages was used for these statistical analyses (QuantPsych, Outliers, car, RcmdMisc, qdata, lmtest, tseries, lsmeans, lsr, afex, effectsize, and ggplot2).

\section{Results}

\section{Interrater Reliability}

The first step led to the modification of 10 elements as they did not meet the recommendations in terms of interrater reliability (Broc et al., 2016; Hayes \& Krippendorff, 2007). After these modifications, the second interrater reliability analysis discarded eight items. The final questionnaire contains 36 items with interrater reliability ranging from satisfactory to excellent (intraclass correlation coefficient >.7; Krippendorff alpha >.7).

\section{Level of KPA}

Figure 1 shows a pattern of low scores among students on the proposed KPA test raw scores. A large majority of the total sample scores were "inadequate" or "low" for each dimension and across the entire test.

Overall, $77.2 \%$ of the students were included in the inadequate or low total score category $(\mu=4.05 \pm 1.27$ [3.96; 4.14]; Figure 1). As shown in Table 3, except for dimension "efficacy" and "training," the skewness of the data distributions was principally negative for the whole sample. The Levene test reveals that variances were unequal across the KPA dimensions $(p<.05)$, and a Dunn test indicates that the variance differs significantly among all dimensions. The "culture" dimension has the highest variance value $(0.25)$ in contrast to the "benefits/risk" and "efficacy" dimension values (0.07). With regard to the mean values of dimensions, a nonparametric Friedman test revealed a significant dimension effect on the scores $(p<.05)$. Post hoc testing showed that the "culture" score $(1.24 / 2 \pm 0.5[1.2 ; 1.27])$ was higher than "benefits," principles, recommendations, and training for total $(p<.05)$. The KPA "principles of efficacy" $(\mu=0.51 / 2 \pm$ $0.27[0.49 ; 0.53])$ displayed the lowest average score $(p<.05)$. $Z$ scores of "recommendation" and "benefits" were not significantly different of other categories $(p>.05)$.

\section{Effects of Gender, School, and Grade on the Ranking of KPA (Z Scores)}

Results from the three-way analysis of variance on the different KPA $z$ scores are presented in Table 4, which shows $z$ scores values 
Inadequate level $\square$ Low level $\square$ Sufficient level $\quad$ Excellent level

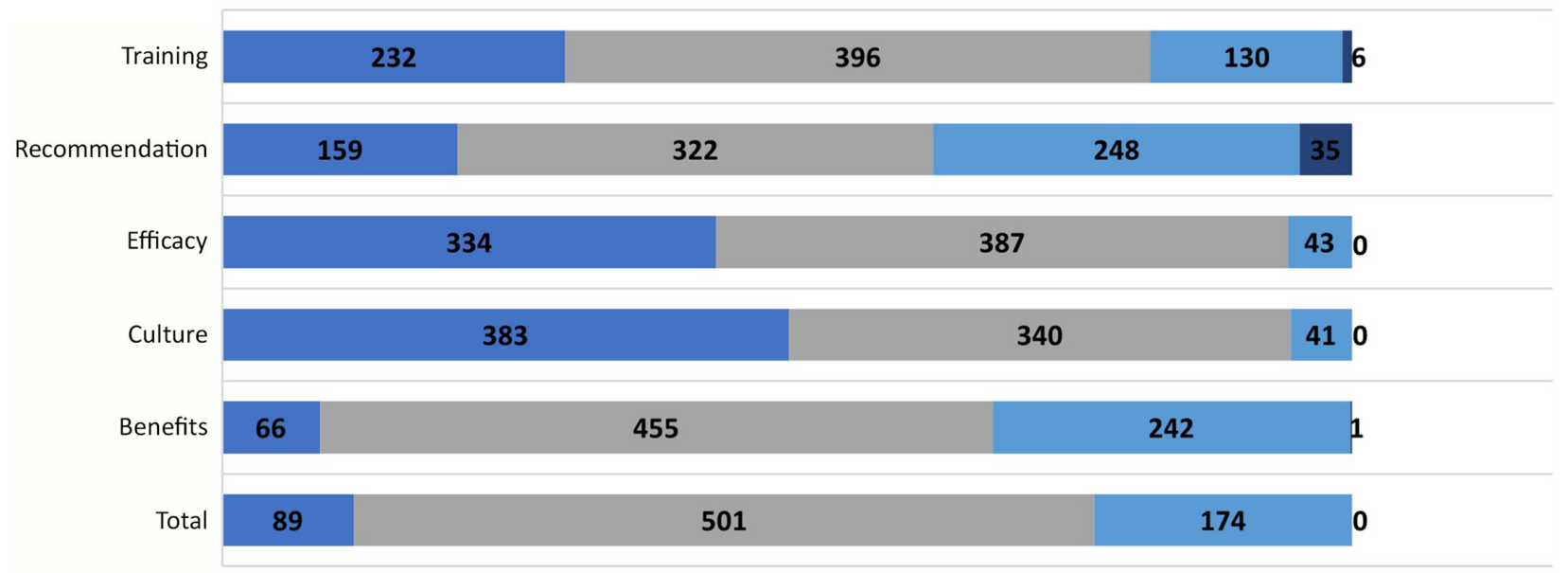

Figure 1 - Levels of KPA on raw scores for the total sample $(n=764)$. Total = total score of KPA; benefits = knowledge of benefits of PA and risks of physical inactivity; culture $=$ knowledge of sports culture; principles $=$ knowledge of principles of efficacy in sports activities; recommendations $=$ knowledge of World Health Organization recommendations; training = knowledge of training process. KPA = knowledge about physical activity. The shaded sections correspond to: inadequate level, low level, sufficient level, and excellent level about KPA.

by gender, school, and grade. Interaction effects for School $\times$ Grade are shown for KPA "culture," $F(3,732)=2.75, p=.04, \eta_{\mathrm{p}}^{2}>.01$, "training," $F(3,732)=3.66, p=.01, \eta_{\mathrm{p}}^{2}>.01$, and "total," $F(3$, 732) $=3.42, p=.01, \eta_{\mathrm{p}}^{2}>.02$.

Results showed significant higher $z$ scores in traditional than in vocational school for KPA "principles," $0.03 \pm 1$ versus $-0.13 \pm$ $0.01, F(1,732)=19.42, p=5.91 \mathrm{e}-05, \eta_{\mathrm{p}}^{2}>.03$, "benefits," $0.08 \pm$ 0.95 versus $-0.36 \pm 1.13, F(1,732)=16.32, p=1.2 \mathrm{e}-05, \eta_{\mathrm{p}}^{2}>.02$, "culture," $0.08 \pm 0.95$ versus $-0.35 \pm 1.14, \quad F(1,732)=18.32$, $p=2.11 \mathrm{e}-05, \eta_{\mathrm{p}}^{2}>.02$, "training," $0.06 \pm 0.96$ versus $-0.32 \pm 1.1$, $F(1,732)=34.97, p=5.12 \mathrm{e}-09, \eta_{\mathrm{p}}^{2}>.05$, and "total," $0.01 \pm 0.94$ versus $-0.46 \pm 1.13, F(1,732)=32.57, p=1.67 \mathrm{e}-08, \eta_{\mathrm{p}}^{2}>.04$.

Within group differences across grades are shown only for the traditional school with higher $z$ scores for the 12th grade than for 10 th grade in KPA "principles" $(0.38 \pm 0.88$ vs. $-0.06 \pm 0.94$, $p=.01$; Figure 2 ). Also, no gender effects were observed in the data $(p>.05)$.

Differences in vocational versus traditional school for the same grades are displayed in Figure 2. No significant differences were found between Grades 9 and 11 in any KPA dimension between participants in the two categories of institutions. For the 10th grade, $z$ scores are higher in traditional, than in vocational programs for KPA "culture" $(0.07 \pm 0.98$ vs. $-0.55 \pm 0.1 ; p=.03)$ and KPA "training" $(0.03 \pm 0.98$ vs. $-0.51 \pm 0.90 ; p=.02)$. For the 12 th grade, $z$ scores are higher in traditional than in vocational institution for KPA "training" $(0.33 \pm 0.88$ vs. $-0.72 \pm 1.22$; $p=.01)$ and KPA "total" $(0.34 \pm 0.85$ vs. $-0.65 \pm 1.21 ; p=.02)$.

\section{Discussion}

The aim of this study was to assess the evolution of the level of KPA in French adolescents (9th to 12th grade) according to gender, school, and grade. Key findings showed that, overall, students enrolled in vocational schools tended to have lower KPA scores than those enrolled in traditional schools, especially in Grade 12. Although students in the traditional program improve their knowledge of the principles of effectiveness in sports activities as they progress through their academic years, KPA does not significantly improve from Grades 9 to 12 . KPA seems to be a forgotten dimension in the formation of a physically literate individual in French high schools.

\section{Two Schools, Two Different Paths to Acquiring KPA}

This study revealed an interaction effect between grade and school on KPA $z$ scores (Table 4). This outcome shows a different evolution in the $z$ scores of students according to the type of school, demonstrating a significant improvement for understanding of KPA "principles" only in traditional school programs. Also, total KPA $z$ scores were significantly higher in traditional than in vocational institution at the end of schooling. These results are consistent with previous studies in the literature showing an effect of educational level on KPA (Bennett et al., 2009; Kari et al., 2020; Kay et al., 2014). In France, these results are confirmed by the consecutive Program for International Student Assessment (OCDE \& Bartilla, 2017), which highlight significant differences between the performance level of French pupils in traditional and vocational institutions in certain subjects (e.g., French and Mathematics). Our results suggested that these differences also exist on the KPA level. While all students have the same initial level of KPA in 9th grade, our results show that knowledge development process differs according to the school type, differentiated by traditional and vocational curricula, in 10th, 11 th, and 12 th grades. Indeed, general curriculum students become more knowledgeable about principles of efficacy in sport activities, although the effect size remains small $\left(\eta^{2}=.01\right)$. Students enrolled in vocational high school, on the other hand, remain stagnant in their levels of KPA. These results suggest that promoting KPA should be seriously considered to reduce inequalities among students. Students in vocational schools have a cumulative disadvantage: this group is generally less successful academically in general (Palheta, 2016), but also in terms of adherence to PA recommendations (Hankonen et al., 2020). Our results highlight that this group is less successful in KPA, but also that the instruction provided throughout high school does not help them improve their KPA. Further studies are needed to better 
Table 3 Descriptive Statistics of Knowledge About Physical Activity by School, Gender, and for Total Sample $(N=764)$

\begin{tabular}{|c|c|c|c|c|c|c|c|c|}
\hline School & $N$ & $S D$ & Mean (/2) & SE & Kurtosis & SE & Skewness & SE \\
\hline \multicolumn{9}{|c|}{ Benefits (2 points) } \\
\hline Traditional & 636 & 0.25 & 0.85 & 0.01 & 0.67 & 0.19 & -0.50 & 0.10 \\
\hline Vocational & 128 & 0.30 & 0.73 & 0.03 & -0.07 & 0.43 & -0.68 & 0.21 \\
\hline Girl & 477 & 0.26 & 0.82 & 0.01 & 0.30 & 0.22 & -0.51 & 0.11 \\
\hline Boy & 287 & 0.26 & 0.84 & 0.01 & 1.40 & 0.29 & -0.80 & 0.14 \\
\hline Total & 764 & 0.26 & 0.83 & 0.01 & 0.69 & 0.18 & -0.61 & 0.09 \\
\hline \multicolumn{9}{|c|}{ Recommendation (2 points) } \\
\hline Traditional & 636 & 0.39 & 0.81 & 0.02 & -0.59 & 0.19 & 0.03 & 0.10 \\
\hline Vocational & 128 & 0.40 & 0.74 & 0.03 & -0.81 & 0.43 & -0.17 & 0.21 \\
\hline Girl & 477 & 0.39 & 0.80 & 0.02 & -0.69 & 0.22 & -0.21 & 0.11 \\
\hline Boy & 287 & 0.40 & 0.80 & 0.23 & -0.46 & 0.29 & -0.03 & 0.14 \\
\hline Total & 764 & 0.39 & 0.80 & 0.01 & -0.60 & 0.18 & 0.00 & 0.09 \\
\hline \multicolumn{9}{|c|}{ Training (2 points) } \\
\hline Traditional & 636 & 0.32 & 0.70 & 0.01 & -0.32 & 0.19 & 0.13 & 0.10 \\
\hline Vocational & 128 & 0.32 & 0.52 & 0.03 & -0.18 & 0.43 & 0.47 & 0.21 \\
\hline Girl & 477 & 0.33 & 0.65 & 0.01 & -0.31 & 0.22 & 0.30 & 0.11 \\
\hline Boy & 287 & 0.32 & 0.71 & 0.02 & -0.31 & 0.28 & -0.09 & 0.14 \\
\hline Total & 764 & 0.33 & 0.67 & 0.01 & -0.37 & 0.18 & 0.15 & 0.09 \\
\hline \multicolumn{9}{|c|}{ Efficacy (2 points0 } \\
\hline Traditional & 636 & 0.26 & 0.53 & 0.01 & -0.28 & 0.19 & 0.23 & 0.10 \\
\hline Vocational & 128 & 0.29 & 0.43 & 0.03 & -0.14 & 0.43 & 0.57 & 0.21 \\
\hline Girl & 477 & 0.27 & 0.50 & 0.01 & -0.19 & 0.22 & 0.42 & 0.11 \\
\hline Boys & 287 & 0.25 & 0.54 & 0.02 & -0.37 & 0.29 & -0.41 & 0.14 \\
\hline Total & 764 & 0.27 & 0.52 & 0.01 & -0.31 & 0.18 & 0.25 & 0.09 \\
\hline \multicolumn{9}{|c|}{ Culture (2 points) } \\
\hline Traditional & 636 & 0.48 & 1.28 & 0.02 & -0.16 & 0.19 & -0.67 & 0.10 \\
\hline Vocational & 128 & 0.57 & 1.05 & 0.05 & -0.87 & 0.43 & -0.37 & 0.21 \\
\hline Girl & 477 & 0.51 & 1.23 & 0.24 & -0.39 & 0.22 & -0.60 & 0.11 \\
\hline Boys & 287 & 0.48 & 1.26 & 0.3 & -0.02 & 0.29 & -0.72 & 0.14 \\
\hline Total & 764 & 0.51 & 1.24 & 0.02 & -0.27 & 0.18 & -0.65 & 0.09 \\
\hline \multicolumn{9}{|c|}{ Total (10 points) } \\
\hline Traditional & 636 & 1.19 & 4.17 & 0.05 & 0.62 & 0.19 & -0.66 & 0.10 \\
\hline Vocational & 128 & 1.47 & 3.46 & 0.13 & -0.37 & 0.43 & -0.39 & 0.21 \\
\hline Girl & 477 & 1.30 & 3.99 & 0.05 & 0.249 & 0.223 & -0.49 & 0.11 \\
\hline Boy & 287 & 1.21 & 4.14 & 0.07 & 1.07 & 0.29 & -1.00 & 0.14 \\
\hline Total & 764 & 1.27 & 4.05 & 0.05 & 0.47 & 0.18 & -0.67 & 0.09 \\
\hline
\end{tabular}

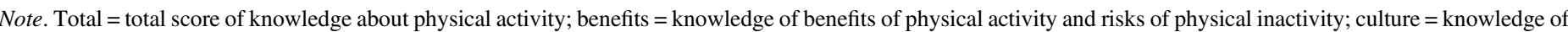

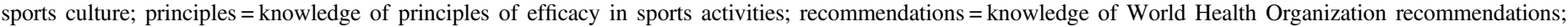
training $=$ knowledge of training process

understand the uniqueness of PA engagement in vocational high school and the type of physical literacy practices that would be most beneficial. However, our results clearly indicate that substantial changes should be made to promote KPA among these students and to promote well-rounded development of physical literacy through high school.

The results of the current study contribute to findings from studies on cognitive dimensions of physical literacy showing that KPA level of Canadian youth increases from 9 to 12 years of age (Longmuir et al., 2018) and from seventh to ninth Grade (Blanchard et al., 2020). Our study suggests that, in France, after Grade 9, there is weak, or no KPA development depending on school while knowledge development should be a dynamic aspect. It would be interesting to conduct a study to explore this issue on an international level, to contribute to the initial findings of Blanchard et al. (2020) and Longmuir et al. (2018).

\section{An Overall Low Level of KPA for Boys and Girls in High School in the Majority of Dimensions}

Overall, the results showed a low KPA level for adolescents across gender, school, and grades. "Culture" dimension showed the highest score with an average score of 1.24 points on a two scale points. Our results corroborate previous findings in the 
Table 4 Z-Scores Values in Relation With Gender, School and Grade and School, Gender, and Grade Effects From a Three-Ways Analysis of Variance

\begin{tabular}{|c|c|c|c|c|c|c|}
\hline Variables & Total & Benefits & Culture & Principles & Recommendations & Training \\
\hline \multicolumn{7}{|l|}{ Gender } \\
\hline Boys & $0.09 \pm 0.96$ & $0.03 \pm 0.98$ & $0.05 \pm 0.97$ & $0 \pm 1.02$ & $0.12 \pm 0.97$ & $0.1 \pm 0.96$ \\
\hline Girls & $-0.04 \pm 1.01$ & $0 \pm 1.01$ & $-0.02 \pm 1.02$ & $0.01 \pm 1$ & $-0.05 \pm 1$ & $-0.07 \pm 1.01$ \\
\hline \multicolumn{7}{|l|}{ School } \\
\hline Traditional & $0.1 \pm 0.94 *$ & $0.08 \pm 0.95^{*}$ & $0.08 \pm 0.95^{*}$ & $0.03 \pm 1 *$ & $0.1 \pm 0.97$ & $0.06 \pm 0.96^{*}$ \\
\hline Vocational & $-0.46 \pm 1.13$ & $-0.36 \pm 1.13$ & $-0.35 \pm 1.14$ & $-0.13 \pm .01$ & $-0.44 \pm 1$ & $-0.32 \pm 1.1$ \\
\hline \multicolumn{7}{|l|}{ Grade } \\
\hline 9th & $0.03 \pm 0.92$ & $0.08 \pm 1$ & $0.04 \pm 0.93$ & $-0.03 \pm 0.95$ & $0.03 \pm 1.1$ & $0.01 \pm 0.98$ \\
\hline 10 th & $-0.12 \pm 1.05$ & $-0.12 \pm 1.01$ & $-0.05 \pm 1.06$ & $0.09 \pm 1.05$ & $-0.08 \pm 1.01$ & $-0.14 \pm 0.99$ \\
\hline 11th & $0.11 \pm 0.95$ & $0.06 \pm 0.95$ & $0.06 \pm 0.96$ & $0.15 \pm 1.04$ & $0.09 \pm 0.95$ & $0.05 \pm 0.95$ \\
\hline 12 th & $0.05 \pm 0.12$ & $0.06 \pm 1.07$ & $-0.02 \pm 1.05$ & $-0.02 \pm 0.91$ & $0.04 \pm 1.1$ & $0.17 \pm 1.09$ \\
\hline \multicolumn{7}{|l|}{ Simple effects } \\
\hline Gender & NS & NS & NS & NS & NS & NS \\
\hline School & $\begin{array}{c}p=1.67 \mathrm{e}-08 \\
\eta_{\mathrm{p}}^{2}>.04\end{array}$ & $\begin{array}{c}p=5.91 \mathrm{e}-05 \\
\eta_{\mathrm{p}}^{2}>.02\end{array}$ & $\begin{array}{c}p=2.11 \mathrm{e}-05 \\
\eta_{\mathrm{p}}^{2}>.02\end{array}$ & $\begin{array}{c}p=1.2 \mathrm{e}-05 \\
\eta_{\mathrm{p}}^{2}>.02\end{array}$ & NS & $\begin{array}{c}p=5.12 \mathrm{e}-09 \\
\eta_{\mathrm{p}}^{2}>.04\end{array}$ \\
\hline Grade & NS & NS & NS & $\begin{array}{c}p=.03 \\
\eta_{p}^{2}>.01\end{array}$ & NS & NS \\
\hline \multicolumn{7}{|l|}{ Interactions effects } \\
\hline Gender $\times$ Grade & NS & NS & NS & NS & NS & NS \\
\hline Gender $\times$ School & NS & NS & NS & NS & NS & NS \\
\hline School $\times$ Grade & $\begin{array}{c}p=.02 \\
\eta_{p}^{2}>.01\end{array}$ & NS & $\begin{array}{c}p=.04 \\
\eta_{p}^{2}>.01\end{array}$ & NS & NS & $\begin{array}{c}p=.01 \\
\eta_{p}^{2}>.01\end{array}$ \\
\hline Gender $\times$ School $\times$ Grade & NS & NS & NS & NS & NS & NS \\
\hline
\end{tabular}

literature which have already highlighted the weakness of the KPA level in different populations (Kay et al., 2014; Hunter et al., 2014; Chen \& Nam, 2017), even among health professionals (Yona et al., 2019). The data also confirm findings of studies suggesting that the PE curriculum does not focus enough on the KPA dimension to promote active lifestyles (Kirk, 2005) and adequately nurture the cognitive dimension of physical literacy. The exception that is highlighted here, concerning knowledge of "sports culture" and the development of "principles of efficacy" KPA for students enrolled in traditional programs, can be linked to the specificity of the French PE curriculum, which is largely focused on the learning of traditional sports (Combaz \& Hoibian, 2009).

No gender effect was detected in any KPA dimensions. Those results are aligned with data from previous studies showing KPA did not differ as a function of gender in children and adolescents (Blanchard et al., 2020; Longmuir et al., 2018). However, other studies indicate that females tend to score higher in general subjects (OCDE \& Bartilla, 2017) or in KPA in adult populations (>18 years; Bennett et al., 2009; Kay et al., 2014; Moore et al., 2010). The KPA gap after high school graduation seems to widen and requires further investigation, possibly focusing on the increasing interest of women in health literacy (Sørensen et al., 2015). However, these conclusions remain speculative, and further study is needed to understand these differences in gender throughout the lifecourse.

\section{Limitations and Perspectives}

In the current study, the data were obtained with a cross-sectional methodology, and future research using longitudinal study design is needed, allowing a more in-depth analysis of KPA development across high school grades. However, the lack of differences between the two types of school at the beginning of high school education allows us to conclude that the development of KPA seems to differ according to the educational career path of the pupils. A second limitation is linked to the lack of a validated KPA measurement tool. We have attempted to address this weakness by creating a test through consensus, assessment scales through a triangulation process, validating the response scales by harnessing expert PE specialists' knowledge, and testing the reliability of the scores. $Z$ scores allowed us to compare each sample's scores and ranking of students according to age and gender-based data norms.

Future investigations are needed to identify which knowledge is actually taught in PE lessons with the involvement of PE teachers and how much is understood and retained by pupils. Several studies have highlighted significant differences between real and formal curricula (Perrenoud, 1993), questioning the difference between what is supposed to be learned (the formal curriculum) and what is actually implemented in PE classes (the real curriculum). These analyses could make it possible to improve the quality of PE teaching from the point of view of the knowledge transmitted, particularly in the case of school type and PA disadvantaged pupils. 

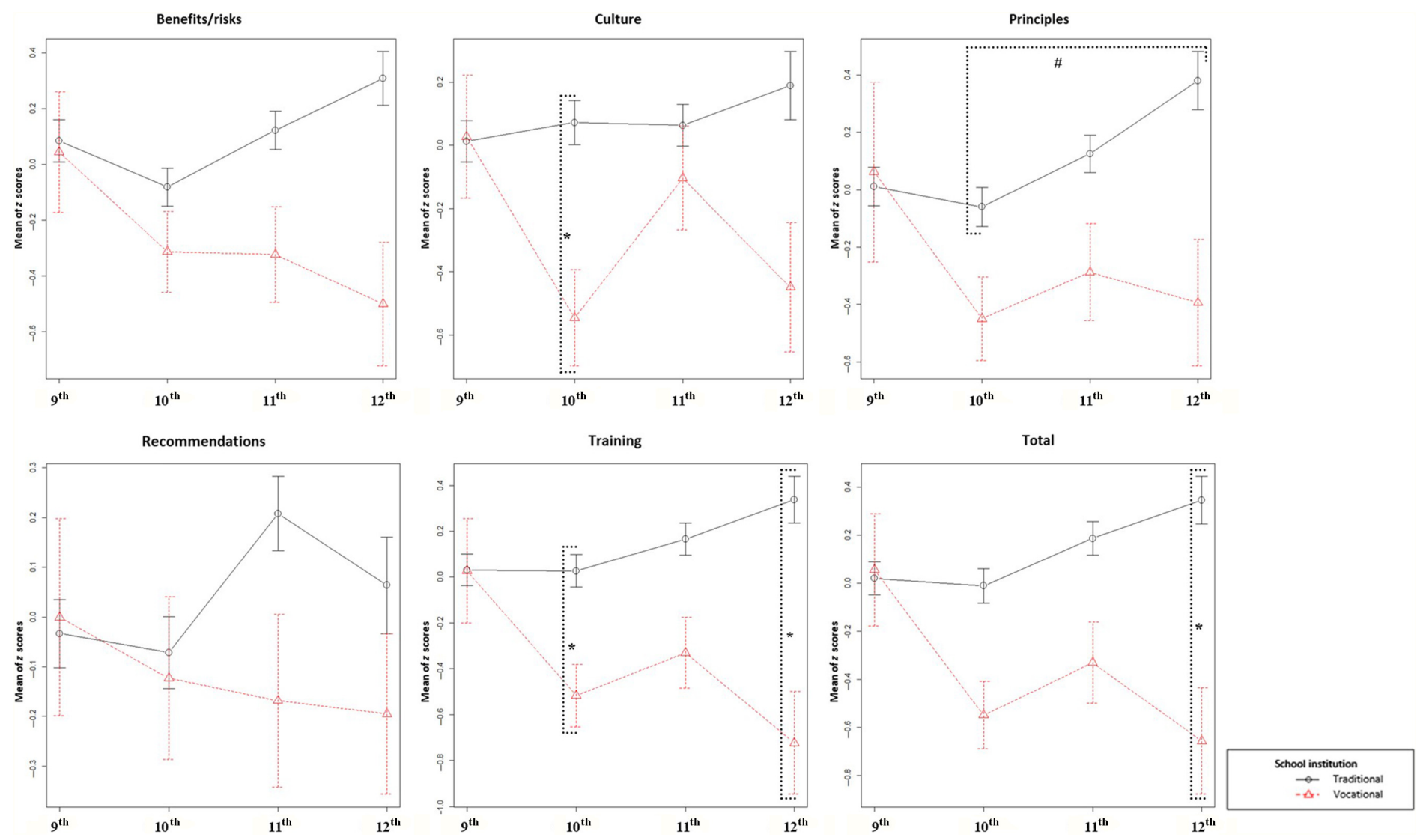

Figure 2 - The $z$ scores values by grade and school for the different dimensions of knowledge about physical activity and total score. *Significant differences between traditional versus vocational school for fixed grade level. \#Significant differences between grade levels for the same school.

\section{Conclusion}

The KPA development constitutes one of the conditions for sustainable PA engagement (Parcel \& Baranowski, 1981; Rudd \& Glanz, 1990; Cairney et al., 2019). Our study reveals a lack of development of KPA in high school, especially in vocational students. Our results challenge PE teaching strategies to ensure that all students are given access to knowledge to lead active, healthy lifestyles through well-rounded physical literacy. This question must be at the heart of current reflections, given the appetite of young people for self-organized PA (Muller, 2018).

\section{References}

Aguert, M., \& Capel, A. (2018). Mieux comprendre les scores z pour bien les utiliser. Rééducation Orthophonique, 274, 61-85. https://www. unicaen.fr/recherche/mrsh/system/files/Marc\%20Aguert/Aguert\% 20\&\%20Capel\%20(2018)\%20PrePrint.pdf

Barnett, L.M., Stodden, D., Cohen, K.E., Smith, J.J., Lubans, D.R., Lenoir, M., Iivonen, S., Miller, A.D., Laukkanen, A., Dudley, D., Lander, N.J., Brown, H., \& Morgan, P.J. (2016). Fundamental movement skills: An important focus. Journal of Teaching in Physical Education, 35(3), 219-225. https://doi.org/10.1123/jtpe.2014-0209

Bartko, J.J. (1966). The intraclass correlation coefficient as a measure of reliability. Psychological Reports, 19(1), 3-11. https://doi.org/10. 2466/pr0.1966.19.1.3
Bennett, G.G., Wolin, K.Y., Puleo, E.M., Mâsse, L.C., \& Atienza, A.A. (2009). Awareness of national physical activity recommendations for health promotion among US adults. Medicine \& Science in Sports \& Exercise, 41(10), 1849-1855. https://doi.org/10.1249/MSS.0b013e $3181 \mathrm{a} 52100$

Blanchard, J., Wyk, N.V., Ertel, E., Alpous, A., \& Longmuir, P.E. (2020). Canadian Assessment of Physical Literacy in grades 7-9 (1216 years): Preliminary validity and descriptive results. Journal of Sports Sciences, 38(2), 177-186. https://doi.org/10.1080/02640414. 2019.1689076

Broc, G., Carlsberg, M., Cazauvieilh, C., Faury, S., Loyal, D., \& Atzeni, T. (2016). Stats faciles avec R : Guide pratique (1st ed.). De Boeck supérieur. https://www.deboecksuperieur.com/ouvrage/978280730 4789-stats-faciles-avec-r

Cairney, J., Dudley, D., Kwan, M., Bulten, R., \& Kriellaars, D. (2019). Physical literacy, physical activity and health: Toward an evidenceinformed conceptual model. Sports Medicine, 49(3), 371-383. https://doi.org/10.1007/s40279-019-01063-3

Cale, L., \& Harris, J. (2018). The role of knowledge and understanding in fostering physical literacy. Journal of Teaching in Physical Education, 37(3), 280-287. https://doi.org/10.1123/jtpe.2018-0134

Chen, S., Lin, Y., \& Schaben, J. (2017). To move more and sit less: Does physical activity/fitness knowledge matter in youth? Journal of Teaching in Physical Education, 36(2), 1-27. https://doi.org/10. 1123/jtpe.2016-0137

Chen, S., \& Nam, Y.H. (2017). Energy balance education in schools: The role of student knowledge. European Physical Education Review, 23(2), 157-170. https://doi.org/10.1177/1356336X16641661 
Cohen, J. (1988). Statistical power analysis for the behavioral sciences (2nd ed.). Routledge. https://www.taylorfrancis.com/books/mono/ 10.4324/9780203771587/statistical-power-analysis-behavioralsciences-jacob-cohen

Combaz, G., \& Hoibian, O. (2009). Quelle culture corporelle à l'école ? Entre tradition sportive et renouvellement des pratiques sociales1980-2006. Sciences sociales et sport, 2(1), 93-124. https://doi.org/ 10.3917/rsss.002.0093

Duru-Bellat, M., \& Perretier, E. (2007). L'orientation dans le système éducatif français, au collège et au lycée. Haut conseil de l'éducation. https://halshs.archives-ouvertes.fr/halshs-00325099

Edwards, L.C., Bryant, A.S., Keegan, R.J., Morgan, K., \& Jones, A.M. (2017). Definitions, foundations and associations of physical literacy: A systematic review. Sports Medicine, 47(1), 113-126. https://doi. org/10.1007/s40279-016-0560-7

Ennis, C.D. (2015). Knowledge, transfer, and innovation in physical literacy curricula. Journal of Sport and Health Science, 4(2), 119124. https://doi.org/10.1016/j.jshs.2015.03.001

Ennis, C.D. (2007). Defining learning as conceptual change in physical education and physical activity settings. Research Quarterly for Exercise and Sport, 78(3), 138-150. https://doi.org/10.1080/ 02701367.2007.10599411

Fredriksson, S.V., Alley, S.J., Rebar, A.L., Hayman, M., Vandelanotte, C., \& Schoeppe, S. (2018). How are different levels of knowledge about physical activity associated with physical activity behaviour in Australian adults? PLoS One, 13(11), e0207003-10, https://doi. org/10.1371/journal.pone.0207003

Guthold, R., Stevens, G.A., Riley, L.M., \& Bull, F.C. (2018). Worldwide trends in insufficient physical activity from 2001 to 2016 : A pooled analysis of 358 population-based surveys with 1.9 million participants. The Lancet. Global Health, 6(10), 1077-1086. https://doi.org/ 10.1016/S2214-109X(18)30357-7

Hankonen, N., Absetz, P., \& Araújo-Soares, V. (2020). Changing activity behaviours in vocational school students: The stepwise development and optimised content of the "let's move it" intervention. Health Psychology and Behavioral Medicine, 8(1), 440-460. https://doi.org/ 10.1080/21642850.2020.1813036

Hayes, A.F., \& Krippendorff, K. (2007). Answering the call for a standard reliability measure for coding data. Communication Methods and Measures, 1(1), 77-89. https://doi.org/10.1080/1931245070933 6664

Haynes, S.N., Richard, D.C.S., \& Kubany, E.S. (1995). Content validity in psychological assessment: A functional approach to concepts and methods. Psychological Assessment, 7(3), 238-247. https://doi.org/ 10.1037/1040-3590.7.3.238

Hulteen, R.M., Morgan, P.J., Barnett, L.M., Stodden, D.F., \& Lubans, D.R. (2018). Development of foundational movement skills: A conceptual model for physical activity across the lifespan. Sports Medicine, 48(7), 1533-1540. https://doi.org/10.1007/s40279-0180892-6

Hunter, R.F., Tully, M.A., Donnelly, P., Stevenson, M., \& Kee, F. (2014). Knowledge of UK physical activity guidelines: Implications for better targeted health promotion. Preventive Medicine, 65, 33-39. https:// doi.org/10.1016/j.ypmed.2014.04.016

Kari, J.T., Viinikainen, J., Böckerman, P., Tammelin, T.H., Pitkänen, N., Lehtimäki, T., Pahkala, K., Hirvensalo, M., Raitakari, O.T., \& Pehkonen, J. (2020). Education leads to a more physically active lifestyle: Evidence based on Mendelian randomization. Scandinavian Journal of Medicine \& Science in Sports, 30(7), 1194-1204. https:// doi.org/10.1111/sms.13653

Kay, M.C., Carroll, D.D., Carlson, S.A., \& Fulton, J.E. (2014). Awareness and knowledge of the 2008 Physical Activity Guidelines for
Americans. Journal of Physical Activity and Health, 11(4), 693698. https://doi.org/10.1123/jpah.2012-0171

Keating, X. (2003). The current often implemented fitness tests in physical education programs : Problems and future directions. Quest, 55(2), 141-160. https://doi.org/10.1080/00336297.2003.10491796

Keating, X.D., Chen, L., Guan, J., Harrison, L., \& Dauenhauer, B. (2009). Urban minority ninth-grade students' health-related fitness knowledge. Research Quarterly for Exercise and Sport, 80(4), 747-755. https://doi.org/10.1080/02701367.2009.10599616

Keegan, R.J., Barnett, L.M., Dudley, D.A., Telford, R.D., Lubans, D.R., Bryant, A.S., Roberts, W.M., Morgan, P.J., Schranz, N.K., Weissensteiner, J.R., Vella, S.A., Salmon, J., Ziviani, J., Okely, A.D., Wainwright, N., \& Evans, J.R. (2019). Defining physical literacy for application in Australia: A modified Delphi method. Journal of Teaching in Physical Education, 38(2), 105-118. https://doi.org/10. 1123/jtpe.2018-0264

Kirk, D. (2005). Physical education, youth sport and lifelong participation: The importance of early learning experiences. European Physical Education Review, 11(3), 239-255. https://doi.org/10.1177/ 1356336X05056649

Kohl, H.W., Craig, C.L., Lambert, E.V., Inoue, S., Alkandari, J.R., Leetongin, G., \& Kahlmeier, S. (2012). The pandemic of physical inactivity: Global action for public health. The Lancet, 380(9838), 294-305. https://doi.org/10.1016/S0140-6736(12)60898-8

Lawshe, C.H. (1975). A quantitative approach to content validity. Personnel Psychology, 28(4), 563-575. https://doi.org/10.1111/j.17446570.1975.tb01393.x

Lincoln, Y.S., \& Guba, E. (1985). Naturalistic inquiry (1st ed.). Sage. https://us.sagepub.com/en-us/nam/naturalistic-inquiry/book842

Longmuir, P.E., Woodruff, S.J., Boyer, C., Lloyd, M., \& Tremblay, M.S. (2018). Physical Literacy Knowledge Questionnaire: Feasibility, validity, and reliability for Canadian children aged 8 to 12 years. BMC Public Health, 18(2), 19-29. https://doi.org/10.1186/s12889018-5890-y

Ministère de l'Education Nationale. (2010). Bulletin officiel spécial $n^{\circ} 4 d u$ 29 avril 2010 Programme d'éducation physique et sportive pour les lycées d'enseignement général et technologique. http://media. education.gouv.fr/file/special_4/73/3/education_physique_sportive_ 143733.pdf

Ministère de l'Education Nationale. (2018). Égalité entre filles et garçons. https://www.education.gouv.fr/egalite-entre-les-filles-et-les-garcons9047

Moore, L.V., Fulton, J., Kruger, J., \& McDivitt, J. (2010). Knowledge of physical activity guidelines among adults in the United States, HealthStyles 2003-2005. Journal of Physical Activity and Health, 7(2), 141-149. https://doi.org/10.1123/jpah.7.2.141

Morrow, J., Krzewinski-Malone, J., Jackson, A., Bungum, T., \& Fitzgerald, S. (2004). American adults' knowledge of exercise recommendations. Research Quarterly for Exercise and Sport, 75, 231-237. https://doi.org/10.1080/02701367.2004.10609156

Muller, J. (2018). Les jeunes aiment le sport ... de préférence sans contrainte. Consommation et modes de vie-CRÉDOC, 297, 1-4. https://www.credoc.fr/publications/les-jeunes-aiment-le-sport-depreference-sans-contrainte

OCDE \& Bartillat. (2017). L'enquête OCDE-PISA : Les défis pour la France (1st ed.). OECD. https://doi.org/10.1787/9789264279537-fr

Palheta, U. (2012). La domination scolaire : Sociologie de l'enseignement professionnel et de son public (1st ed.). Presses Univ. de France. https://www.cairn.info/la-domination-scolaire--9782130592211.htm

Parcel, G.S., \& Baranowski, T. (1981). Social learning theory and health education. Health Education, 12(3), 14-18. https://doi.org/10.1080/ 00970050.1981.10618149 
Pate, R.R., Davis, M.G., Robinson, T.N., Stone, E.J., McKenzie, T.L., \& Young, J.C. (2006). Promoting Physical Activity in Children and Youth: A Leadership Role for Schools: A Scientific Statement From the American Heart Association Council on Nutrition, Physical Activity, and Metabolism (Physical Activity Committee) in Collaboration With the Councils on Cardiovascular Disease in the Young and Cardiovascular Nursing. Circulation, 114(11), 1214-1224. https:// doi.org/10.1161/CIRCULATIONAHA.106.177052

Perrenoud, P. (1993). Curriculum : le formel, le réel, le caché. In J. Houssaye (Eds.), La pédagogie : une encyclopédie pour aujourd'hui (1st ed., pp. 61-76). ESF.

Placek, J.H., Griffin, L.L., Dodds, P., Raymond, C., Tremino, F., \& James, A. (2001). Middle school students' conceptions of fitness: The long road to a healthy lifestyle. Journal of Teaching in Physical Education, 20(4), 314-323. https://doi.org/10.1123/jtpe.20.4.314

Rudd, J., \& Glanz, K. (1990). How individuals use information for health action: Consumer information processing. In K. Glanz, F. MarcusLewis, \& B. K. Rimer (Eds.), Health behaviorand health education: Theory research and practice (pp. 115-139). Jossey-Bass.

Shrout, P.E., \& Fleiss, J.L. (1979). Intraclass correlations: Uses in assessing rater reliability. Psychological Bulletin, 86(2), 420-428. https:// doi.org/10.1037/0033-2909.86.2.420

Sørensen, K., Pelikan, J.M., Röthlin, F., Ganahl, K., Slonska, Z., Doyle, G., Fullam, J., Kondilis, B., Agrafiotis, D., Uiters, E., Falcon, M., Mensing, M., Tchamov, K., van den Broucke, S., \& Brand, H. (2015). Health literacy in Europe: Comparative results of the European health literacy survey (HLS-EU). The European Journal of Public Health, 25(6), 1053-1058. https://doi.org/10.1093/eurpub/ckv043
Sport Australia. (2020). Australian Physical Literacy Framework. Australian Government. https://www.sportaus.gov.au/physical_literacy

Strauss, A., \& Corbin, J.M. (1990). Basics of qualitative research: Grounded theory procedures and techniques (1st ed.). Sage.

Tanner, D., \& Tanner, L. (2006). Curriculum development: Theory into practice (4th ed.). Pearson.

UNESCO. (2015). Quality Physical Education (QPE) guidelines for policy-makers. http://unescoittralee.com/wp-content/uploads/2015/ 01/Quaility-Physical-Education-Guidelines-for-Policy-Makers.pdf

Van Sluijs, E.M.F., McMinn, A.M., \& Griffin, S.J. (2007). Effectiveness of interventions to promote physical activity in children and adolescents: Systematic review of controlled trials. BMJ, 335(7622), 703-716. https://doi.org/10.1136/bmj.39320.843947.BE

Whitehead, M. (2001). The concept of physical literacy. European Journal of Physical Education, 6(2), 127-138. https://doi.org/10.1080/ 1740898010060205

Whitehead, M. (2010). Physical literacy: Throughout the lifecourse (1st ed.). Routledge. https://doi.org/10.4324/9780203881903

Whitehead, M. (2019). Physical literacy across the world (1st ed.). Routledge. https://doi.org/10.4324/9780203702697

World Health Organization. (2020). WHO guidelines on physical activity and sedentary behaviour. https://www.who.int/publications/i/item/ 9789240015128

Yona, T., Ben Ami, N., Azmon, M., Weisman, A., \& Keshet, N. (2019). Physiotherapists lack knowledge of the WHO physical activity guidelines. A local or a global problem? Musculoskeletal Science and Practice, 43, 70-75. https://doi.org/10.1016/j.msksp.2019. 07.007 